\title{
THE STUDY OF QUALITY OF LIFE IN PATIENT WITH VITILIGO
}

Poudyal $Y^{1}$, Parajuli N $N^{2}$ Dahal SC ${ }^{3}, J_{\text {ha } C B^{4}}$

\section{Affiliation}

1. Constultant Dermatologist, Sarnath Skin Centre, Shantipath, Bhairahawa, Nepal

2. Assistant Professor, Department of Dermatology, National Academy of Medical Sciences- Bir Hospital, Mahaboudha, Kathmandu, Nepal.

3. Medical Recording and Analyst, Civil Service Hospital, Minbhawan, Kathmandu, Nepal.

4. Senior Constultant Dermatologist. Department of Dermatology, Koshi Hospital, Rangeli Road, Biratnagar, Nepal.

\section{ARTICLE INFO}

Received : 17 July, 2020

Accepted : 24 November, 2020

Published : 22 December, 2020

(c) Authors retain copyright and grant the journal right of first publication with the work simultaneously licensed under Creative Commons Attribution License CC - BY 4.0 that allows others to share the work with an acknowledgment of the work's authorship and initial publication in this journal.

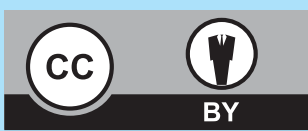

ORA 208

DOI: https://doi.org/10.3126/bjhs.v5i3.33699

\section{* Corresponding Author}

Dr. Yogesh Poudyal

Consultant Dermatologist

Sarnath Skin Centre, Bhairahawa, Nepal

Email ID: neverland791@yahoo.com

ORCID ID: https://orcid.org/0000-0000-0001-6692-5688

\section{Citation}

Poudyal Y, Parajuli N, Dahal SC, Jha CB. The Study of Quality of Life in Patient with Vitiligo. BJHS 2020;5(3)13.1206-1209.

\section{ABSTRACT}

\section{Introduction}

Vitiligo is an acquired, idiopathic and common depigmentation disorder of skin. Strong stigma associated with the disease, its chronic nature, and cosmetic disfigurement often cause distress to patients and may affect the quality of life.

\section{Objective}

To assess the quality of life in patient with vitiligo, using Dermatology life quality index(DLQI) questionnaire.

\section{Methodology}

Total of 212 patients with vitiligo participated in this crosssectional study done at Dermatology and Venereology OPD of Universal College of Medical Science, Bhairahawa, Nepal.. The participants were given DLQI questionnaire consisting of 10 questions to fill up.

\section{Result}

The median DLQI score was 4(6), which showed small effect in quality of life. There was positive association with duration of disease and DLQI score $(p<0.05)$. The highest average score was seen in heading item "symptom and feeling". There was no difference in DLQI score, when compared among gender and among various types of vitiligo.

\section{Conclusion}

Psychological assessment should be done in vitiligo cases, especially in those with long duration of disease.

\section{KEYWORDS}

Quality of life, cross-sectional study, questionnaire, vitiligo 


\section{INTRODUCTION}

Vitiligo refers to an acquired, idiopathic and common de-pigmentation disorder of the skin. The clinically characteristic symptoms of the vitiligo are pale or milk-white macules or patches due to the selective destruction of melanocyte. The prevalence of vitiligo is $0.1 \%$ in Asia. ${ }^{1}$ Since ancient times patient with vitiligo suffered the same mental abuses as lepers. In actual fact vitiligo was referred as 'sweta kustha' meaning white leprosy. ${ }^{2}$ Due to strong stigma in society prevalent for centuries and due to strong contrast in dark skinned individual, it looks more disfiguring, and this may causes distress to the patient. The chronic nature of disease, long term treatment, lack of uniform effective therapy and unpredictable course of disease is often distressing and demoralizing for patient. ${ }^{3}$ All these factors have significant role in affecting the quality of life in patients with vitiligo in Nepal. Studies done in India showed high degree of psychiatric morbidity, with depression being common, in patients with vitiligo. ${ }^{4,5}$

Health-related quality of life(QOL) scales are multidimensional questionnaires given to patients in an attempt to measure the repercussions of their disease and treatment on the psychological, physical and social aspects of daily life. ${ }^{6}$ Dermatology Life Quality Index( DLQI) is a simple 10 question validated questionnaire developed by A. Y. Finlay and G.K. Khan to assess the quality of life. ${ }^{7}$ It has been used to study quality of life in many dermatological diseases. It was seen that quality of life was more impaired in those studies done in Asian Subcontinent than that in European countries, where standard of living is high and people have more fair skin. ${ }^{3-9}$ In Nepal, it was found that vitiligo was considered to be serious condition and believed to have serious consequences and distressing condition and there was false belief of this disease being caused by germs or virus. $^{10}$

After considering the belief of people about vitiligo in Nepal and studies done in various parts of the world about difference in DLQI score varying according to region, this study attempts to find the quality of life of patients with vitiligo living in western region of Nepal.

\section{METHODOLOGY}

This study was done in Dermatology and Venereology OPD of Universal college of Medical Sciences (UCMS), Ranigaon, Bhairahawa, Nepal. This is tertiary care Hospital at western region of Nepal. This cross-sectional study was carried out from January1, 2015 to December31, 2016. The ethical approval was obtained from Institutional Review board of UCMS ( No: UCMS/IRC/040/14 dated: November 7,2014).

All the cases of vitiligo presenting to the OPD with age of 16 years and above and who gave consent, were included in the study. Consecutive sampling method was used for sample collection. The total participants were 212 .

The permission to use the DLQI questionnaire was obtained from the author A.Y. Finlay (University of Wales, College of Medicine, Cardiff, U.K.). The validated Nepali and Hindi versions available from the website were used for data collection. Dermatology Life Quality index(DLQI) consist of 10 questions. ${ }^{7}$ Each question has four alternative responses 'not at all', 'a little', 'a lot' and 'very much' with corresponding score of $0,1,2$ and 3 respectively. The answer not relevant is also scored as 0 . The DLQI is calculated by summing the score of each question, resulting in maximum of 30 and minimum of 0 . The higher the score is, the more quality of life is impaired. The question can also be classified in six heading items: symptom and feeling (question 1 and 2), daily activities(question 3 and 4), Leisure(question 5 and 6), work / school (question 7), personal relationship (question 8 and $9)$, treatment (question 10). The score can be assessed as: score (0-1) indicate no effect on the patient's life, (2-5) indicate small effect on the patient's life, score(6-10) shows moderate effect in patient's life, score(11-20) shows very large effect on the patient's life and score (21-30) shows extremely large effect on the patient's life. ${ }^{11}$

After taking consent from the patients, they were asked to fill the DLQI questionnaire. All the clinical details and total score were recorded on pre-designed proforma. Data was entered in Excel sheet. SPSS version 20 was used to analyze data. Descriptive statistical measures were calculated. Mann-Whitney U test, Kruskal -Wallis test, Spearman's rho correlation analysis were used for data analysis. Level of significance was set at $5 \%(P \leq 0.05)$ and power was set at $80 \%$.

\section{RESULTS}

The total number of participants were 212. Among them 92(43.4\%) were male and $120(56.6 \%)$ were female. The mean age of the participants was $34.01( \pm 15.25)$, with age ranging from 16 years to 78 years.

Five different types of vitiligo were found: Vitiligo Vulgaris (51.4\%), Acrofacial Vitiligo (17.5\%), Vitiligo Universalis (2.8\%), Segmental Vitiligo (14.6\%) and Mucosal Vitiligo (13.7\%). The duration of disease ranged from 15 days to 30 years with median duration of 12 months (44).

The median DLQI score was 4(6) \{Median (Inter Quartile Range) $\}$ with score ranging from 0 to 27.

Comparision of DLQI among male and female showed no significant difference in quality of life. The median average score for male was $4(6)$ and female was 3(6), with p-value (0.875).

On comparision of DLQI score of various types of vitiligo, no statistically significant difference in impairment of quality of life was found.(Table 1)

Table 1: Comparision of DLQI score among the various types of vitiligo.

\begin{tabular}{|c|c|c|}
\hline Types of Vitiligo & Median (Inter Quartile Range) & P-Value \\
\hline Vitiligo Vulgaris & 4 (8) & \\
\hline Acro- Facial Vitiligo & $5 \quad(8)$ & 0.086 \\
\hline Vitiligo Universalis & 4.5 (7) & \\
\hline Segmental Vitiligo & 2 (3) & \\
\hline Mucosal Vitiligo & 3 (4) & \\
\hline
\end{tabular}


The median duration of disease was 12 months (44). When duration of disease in association with quality of life score was seen, it was found that more the duration of disease more the impairment in quality of life, and was statistically significant ( rho:0.296 and $p$ value:0.0001)

When the score was calculated according to the six heading items, the highest score was seen in symptom and feeling, and since vitiligo is mostly asymptomatic disease this score can be attributed to feeling. (Table 2)

Table 2: Mean and Median DLQI score of the sample
according to different heading items
\begin{tabular}{|l|c|c|c|c|}
\hline \multicolumn{1}{|c|}{ Heading Items } & Mean \pm SD & $95 \%$ CI & $\begin{array}{c}\text { Median } \\
\text { (IQ Range) }\end{array}$ & Min - max \\
\hline $\begin{array}{l}\text { Symptoms and feeling } \\
\text { (Q1-2) }\end{array}$ & $0.77 \pm 0.69$ & $0.68-0.86$ & $0.5(1.50)$ & $0-3$ \\
\hline Daily Activities (Q3-4) & $0.49 \pm 0.72$ & $0.39-0.58$ & $0(0.88)$ & $0-3$ \\
\hline Leisure (Q5-6) & $0.48 \pm 0.71$ & $0.39-0.58$ & $0(0.5)$ & $0-3$ \\
\hline Work and School (Q7) & $0.17 \pm 0.52$ & $0.10-0.24$ & $0(0.00)$ & $0-3$ \\
\hline $\begin{array}{l}\text { Personal Relationship } \\
\text { (Q8- Q9) }\end{array}$ & $0.47 \pm 0.76$ & $0.37-0.57$ & $0(0.5)$ & $0-3$ \\
\hline Treatment (Q10) & $0.61 \pm 0.99$ & $0.48-0.75$ & $0(1.00)$ & $0-3$ \\
\hline
\end{tabular}

\section{DISCUSSION}

There was small effect in quality of life in patients with vitiligo. There was no statistically significant differences in impairment of quality of life among genders, and among types of vitiligo. The duration of disease affected the quality of life.

The median DLQI score of this study was 4(6). This showed small effect in quality of life. Some studies had shown higher average score than our study. ${ }^{3-5,8,12-14}$ Most of these studies were done in South- east Asia and Middle east. The study done in Nepal was slightly less than our study. ${ }^{15}$ The researches done in Europe showed scored less than this study. ${ }^{9,16}$ Due to dark skin, cosmetic disfigurement is seen more in Asian Skin compared to that of European Skin. Though people holds a wrong belief that vitiligo is caused by "Germ or Virus" and believed it to be having serious condition in Nepal, ${ }^{10}$ this study showed only small effect in quality of life. Studies done in other countries sharing same skin color as ours have comparatively higher score than this study. Another study done in Nepal also supports our finding. ${ }^{15}$ So the contrast in color may not be the only reason of high DLQI score as mentioned in previous studies performed in Asia.

Though average score of female was less than male, but the difference was not statistically significant. The studies at different areas from the world have shown different result.

Studies showed the quality of life is affected more in female than male. 4, $, 14,17$ There are studies which showed, no difference in quality of life. ${ }^{3,8,18}$ Studies had mentioned that prevalent belief of contagiocity and cosmetic disfigurement may seem affecting female more than male, but our study did not show any difference in quality of life in terms of gender.

With median score of $5(8)$, the acro-facial type seem to affect Quality of life more than other type. But when compared, there was no statistically significant difference. Study by Radtke MA et al showed that patient with lesion on exposed site and more area of involvement showed more impairment in quality of life. ${ }^{14}$ The study by Al Robaee AA and Sangma LN et al showed the quality of life is more impaired in Universal Vitiligo., 4 Authors had emphasized that increase in body area involvement and lesion on exposed part increases disease related stress. The extent of disease did not seem to affect quality of life in study done by Parsad D etal. ${ }^{8}$ In our study, average score was more in Acrofacial, that is vitiligo mainly at exposed site, but it was not statistically significant. So the vitiligo's distribution or severity of involvement did not have any effect in quality of life.

Our study showed that the duration of disease affects the quality of life. Longer the duration of disease, impairment in quality of life was more. Studies done by Parsad D et al. and Radtke MA supports the finding. ${ }^{8,14}$ Study by Krishna GS et al. showed duration did not affect the quality of life. ${ }^{19}$ The relation of increased duration of vitiligo with DLQI score may be due to cumulative effect of psychological and social problems faced by patients for long duration. It seems that despite the chronic nature of disease and comparatively less harmful condition patients often does not learn to accept the condition. While dealing vitiligo patients with long duration of disease, more psychological support and counseling may be required.

According to the different heading items, the maximum average score was seen in symptom and feeling, followed by treatment . Since vitiligo is asymptomatic disease the score of heading item "symptom and feeling"can be attributed to feeling only. Among various items, feeling scored highest in study done in Nepal. ${ }^{15}$ Studies from India, Italy, China also had same conclusion, but study from Estonia it was second to clothing. ${ }^{4,5,14,22,21}$ The question asked as feeling was "Over the last week, how embarrassed or self conscious have you been due to your skin problem?" Since most of the studies had shown that feeling of embarrassment and selfconsciousness about the disease was most important part that affects the quality of life, this aspect should be focused while counseling the patients with vitiligo.

\section{CONCLUSION}

There was small effect in quality of life in patients with Vitiligo. The color contrast seen in vitiligo may not be the reason of low quality of life as concluded in other studies. The quality of life due to vitiligo was not different when compared among the gender. There was no difference in quality of life score among various types of vitiligo. It was seen that longer the duration more the quality of life being affected. Feeling was most important item that affected the quality of life in our study. So the patients with long duration needs more psychological assessment and their feeling should be addressed first.

\section{RECOMMENDATION}

The psychological assessment should be considered in patients with long duration of disease. Consideration should be given to the issue of patient's feeling of embarrassment due to disease, while evaluating their history and in treatment. 


\section{LIMITATION OF THE STUDY}

Though the sample was large as compared to other studies, this study was basically based on vitiligo patient coming to hospital for their problem, and may not completely represent the vitiligo in the general population setting.

\section{ACKNOWLEDGEMENTS}

The authors would like to thank Prof. A. Y. Finlay for his kind permission to use the DLQI questionnaire. The authors would like to thank Dr. Mukti Ghimire for her help in data management and manuscript preparation.

\section{CONFLICT OF INTEREST}

The authors declare that they have no conflict of interest.

\section{FINANCIALDISCLOSURE}

None

\section{REFERENCES}

1) Zhang $Y$, Cai $Y$, Shi $M$, Jiang $S$, Cui $S, W u$, et al. The prevalence of vitiligo: A Meta- Analysis. PloS ONE 2016 Sept 27. 11(9): e0163806. DOI: 10.1371/journal.pone.0163806.

2) Parsad D, Dogra $S$, Kanwar AJ. Quality of life in patients with vitiligo. Health Qual Life Out. 2003 Oct 23.DOI: 10.1186/1477-7525-1-58

3) Al Robaee A A. Assessment of quality of life in Saudi patients with vitiligo in a medical school in Qassim province, Saudi Arabia. Saudi Med J. 2007 Sep;28(9):1414-1417.PMID:17768471

4) Sangma LN, Nath J, Bhagabati D. Quality of life and psychological morbidity in vitiligo patients: A study in a teaching hospital from north-east India. Indian J Dermatol. 2015 Mar 3;60(2): 142146.DOI:10.4103/0019-5154.152508

5) Kota RS, Vora RV, Varma JR, Kota SK, Patel TM, Ganjiwale J. Study on assessment of quality of life and depression in patients of vitiligo. Indian Dermatol Online J. 2019 Mar 15;10(2): 153-157.DOI:10.4103/ idoj.IDOJ_14_18

6) Le Cleach L, Chassany O, Levy A, Wolkenstein P, Chosidow O. Poor reporting of quality of life outcomes in dermatology randomized controlled clinical trials. Dermatology. 2008 Jan 1; 216 (1):4655.DOI:10.1159/000109358

7) Finlay AY, Khan GK. Dermatology Life Quality Index (DLQI) - a simple practical measure for routine clinical use. Clin Exp Dermatol. 1994 May;19(3):210-216.DOI:10.1111/j.1365-2230.1994.tb01167.x.

8) Parsad D, Pandhi R, Dogra S, Kanwar AJ, Kumar B. Dermatology Life Quality Index score in vitiligo and its impact on treatment outcome. Br J Dermatol. 2003 Feb 17;148(2):373-374.DOI: 10.1046/j.13652133.2003.05097_9.x

9) Ongenae K, Van Geel N, De Schepper S, Naeyaert JM. Effect of vitiligo on self -reported health - related quality of life. Br J Dermatol. 2005 June 22;152(6):1165-1172.DOI: 10.1111/j.1365-2133.2005.06456.x.

10) Agrawal $S$, Kumar $A$, Shyngwa PM. Understanding of Nepalese patients with vitiligo about their disease. NJDVL. 2016 Jan 7; 12(1):713.DOI: https://doi.org/10.3126/njdvl.v12i1.10590.

11) Hongbo $Y$, Thomas $C L$, Harrison MA, Salek MS, Finlay AY. Translating the science of quality of life into practice: what do dermatology life quality index score mean. J Invest Dermatol. 2005 Oct 1;125(4):659664.DOI:10.1111/j.0022-202X.2005.23621.x.
12) Aghaei S, Sodaifi M, Jafari P, Mazharinia N, Finlay AY. DLQI scores in vitiligo: reliability and validity of the Persian version. BMC Dermatol. 2004 Aug 4. DOI: 10.1186/1471-5945-4-8.

13) Dolatshahi $M$, Ghazi $P$, Feizy $V$, Hemami MR. Life quality assessment among patients with vitiligo: Comparision of married and single patients in Iran. Indian J Dermatol Venereol Leprol. 2008;74. DOI:10.4103/0378-6323.45141.

14) Radtke MA, Schafer I, Gajur A, Langenbruch A, Augustin M. Willingness to pay and quality of life in patients with vitiligo. $\mathrm{Br} \mathrm{J}$ Dermatol. 2009 June 22;161(1):134-139.DOI:10.1111/j.13652133.2009.09091.x.

15) Amatya B, Pokhrel DB. Assessment and comparision of quality of life in patients with melasma and vitiligo. Kathmandu Univ Med J. 2019; 17(66):114-118.PMID: 32632057

16) Ingordo V, Cazzaniga S, Gentile C,lannazzone SS, Cusano F, Naldi L. Dermatology Life Quality index score in Vitiligo patients: a pilot study among Italian males. G Ital Dermatol Venereol. 2012 Feb;147(1):8390. PMID: 22370571

17) Mashayekhi V, Javidi Z, KiafarB, Manteghi AA, Saadatian V, Esmaeili HA. Quality of life in patients with vitiligo: A descriptive study on 83 patients attending a PUVA therapy unit in Imam Reza Hospital, Mashad. Indian J Dermatol Venereol Leprol. 2010 Sep 7 ;76(5):592. DOI: 10.4103/0378-6323.69097

18) Sawant NS, Vanjari NA, Khopkar UG. Gender differences in depression, coping, Stigma, and quality of life in patients with vitiligo. Dermatology Res Pract. 2019 Apr 2. DOI: 10.1155/2019/6879412.

19) Krishna GS, Ramam $M$, Mehta $M$, Sreenivas VK, Khandpur $S$. Vitiligo impact scale: An instrument to assess the psychological burden of vitiligo. Indian J Dermatol Venereol Leprol. 2013 Feb 23;79(2):205210.DOI:10.4103/0378-6323.107637

20) Wang KY, Wang KH, Zhang ZP. Health-related quality of life and marital quality of vitiligo patients in China. J Eur Acad Dermatol Venereol. 2011 Mar 4;25(4):429-435.DOI:10.1111/j.1468-3083.2010.03808.x.

21) Karelson $M$, Silm $H$, Kingo K. Quality of life and emotional state in vitiligo in an Estonian sample: Comparision with psoriasis and healthy controls. Acta Derm Venereol. 2013 Jul 6;93(4):444-450. DOI:10.2340/00015555-1520. 